\title{
THE INFLUENCE OF LOADING RATE ON CRACK BRIDGING PROCESSES IN $\mathrm{Al}_{2} \mathrm{O}_{3}$
}

\author{
S. TANDON and K. T. FABER \\ Department of Materials Science and Engineering, Robert R. McCormick School of Engineering and \\ Applied Science, Northwestern University, 2225 N. Campus Drive, Evanston, IL 60208-3108, U.S.A.
}

(Received 15 September 1997; accepted in revised form 31 December 1997)

\begin{abstract}
Commercially available alumina of $94 \%$ nominal purity was used to examine the influence of loading rate on toughening mechanisms. For fine-grained alumina, the crack resistance, $K_{\mathrm{R}}$, was found to be independent of crack length and loading rate. Coarse-grained alumina exhibited strongly rising $R$-curves where the initial fracture toughness, $K_{0}$, was found to be independent of the loading rate. The net toughening, $\Delta K_{\mathrm{SS}}$, in coarse-grained alumina was found to decrease with increasing loading rate. Loading rate effects were independent of testing environment. A rate dependent coefficient of friction was incorporated into a crack bridging model to describe the effect of loading rate on toughness in this system. Predictions based on the bridging models, using the measured coefficients of friction for this material system, are in good agreement with the observed phenomenon. (C) 1998 Acta Metallurgica Inc.
\end{abstract}

\section{INTRODUCTION}

Crack bridging by unfractured ligaments in polycrystalline monophase ceramics [1], brittle whiskers [2] or fibers [3] in ceramic composites or by ductile metal particles in cermets [4] is known to provide significant enhancement of the toughness of brittle ceramic materials. Bridging ceramics show resistance $(R-)$ curve behavior [5], a schematic of which is shown in Fig. 1. The fracture toughness of the material increases from initial value $K_{0}$ which represents the intrinsic toughness of the material and achieves a steady state toughness $K_{\max }$ when the bridging zone reaches a constant length. $K_{\max }$ can be written as:

$$
K_{\max }=K_{0}+\Delta K_{\mathrm{SS}}
$$

where $\Delta K_{\mathrm{SS}}$ is the steady state toughening contribution from bridging in the crack wake. A number of issues relating to toughening due to crack bridging have been investigated already. Resistance $(R$ - $)$ curves have been studied for a variety of ceramic materials [6,7], grain sizes [8], test temperatures [9], and specimen geometries [10-12]. Theoretical models also have been developed to predict the fracture and toughening behavior of bridging ceramics $[13,14]$.

However, the influence of loading rate on the bridging processes and on the net toughening, $\Delta K_{\mathrm{SS}}$, has not been explored. The effect of stressing rate or loading rate on strength has been studied in ceramic systems in detail [15-17]. Examination of the fractured surfaces of oxide as well as non-oxide ceramics has provided ample evidence for an intergranular-transgranular transition with the change in crack growth velocity, suggesting that the formu- lation of bridges is affected by loading rate. In this paper, we report the influence of loading rate on toughening in a bridging ceramic. Fine-grained alumina was chosen in this study to serve as the control material. This material fails in a classically brittle fashion (i.e. where toughness is independent of crack length). Coarse-grained alumina, produced by grain growth of the fine-grained material, demonstrates significant resistance curve behavior due to grain bridging behind the crack tip. Experimental results of the net toughening contribution from grain bridging are compared with a rate-dependent modification of Bennison's and Lawn's [14] grain bridging model. The contributions to the net toughening from debonding and frictional pullout of the bridging grains and the effect of loading rate on the individual toughening contributions are evaluated herein.

\section{MODELING THE INFLUENCE OF RATE ON CRACK BRIDGING}

Bennison and Lawn [14] considered toughening from a bridging grain as the combination of two events: debonding of the grain and pullout of the debonded grain. They derived constitutive relationships between the closure stress, $p$, and crack opening, $2 u$, for both debonding and pullout. Figure 2 shows a schematic plot of the closure force, $p$, vs crack opening, $2 u$. Curve $\mathrm{CA}$ is the debonding curve, and the straight line FD represents frictional pullout. The area under the composite curve of debonding and pullout prior to granular fracture is a measure of net toughening enhancement of the debonding-pullout processes for a single bridging grain. If a bridging grain shows full debonding and 


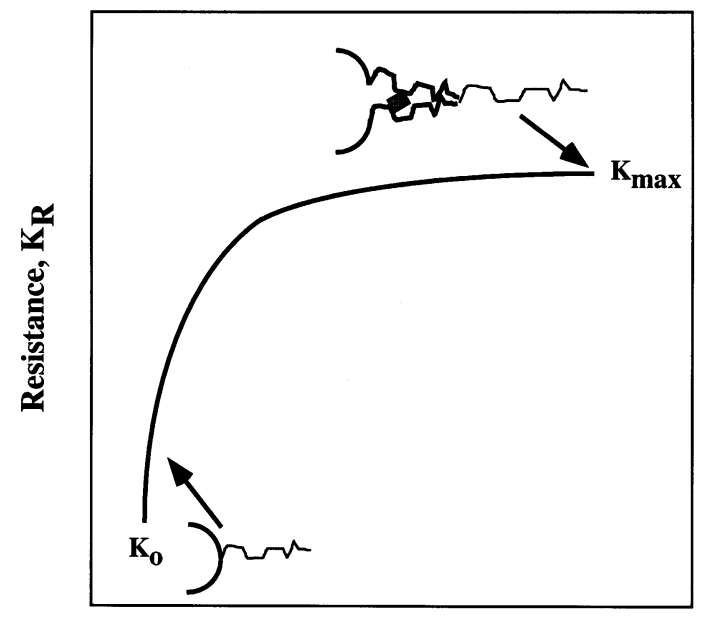

Crack Length, a

Fig. 1. Schematic of a resistance $(R-)$ curve for a brittle ceramic. With crack extension, the resistance to fracture, $K_{\mathrm{R}}$, increases from its initial value, $K_{0}$ and achieves the steady-state value, $K_{\max }$.

full pullout prior to fracture, the net toughening is calculated from the total area bounded by two solid curves CP and PD in Fig. 2.

For such a bridging grain, Bennison and Lawn combined micromechanical force-separation functions with fracture mechanics calculations, and derived relationships for toughness as a function of crack length, $a$. For crack lengths, $a>a^{*}$, at steady state:

$$
\Delta K_{\mathrm{SS}}=K_{\max }-K_{0}=\frac{1}{2} \psi p_{\mathrm{M}} a^{* 1 / 2},
$$

where $\psi$ is a geometry-dependent coefficient, $p_{\mathrm{M}}$ is a scaling quantity and $a^{*}$ is the critical crack length at which the $R$-curve achieves steady state resistance. The quantities $p_{\mathrm{M}}$ and $a^{*}$ are given by following expressions:

$$
\begin{gathered}
p_{\mathrm{M}}=\alpha_{\lambda} \varepsilon_{\mathrm{L}} \alpha_{\mathrm{L}} \mu \sigma_{\mathrm{R}}\left(1-\frac{1}{2 \alpha_{\mathrm{d}}^{2}}\right) \\
a^{*}=\left(\frac{\varepsilon_{\mathrm{L}} \alpha_{\mathrm{L}} E^{\prime} l}{2 \psi K_{0}}\right)^{2},
\end{gathered}
$$

where $\alpha_{\lambda}, \alpha_{\mathrm{L}}$ and $\alpha_{\mathrm{d}}$ are geometrical similitude constants involving grain shape, grain size $(l)$ and bridge spacing. The quantity, $\varepsilon_{\mathrm{L}}$ is the "bridge rupture strain", $E^{\prime}$ is the plain strain Young's modulus of the material and $K_{0}$ is the initial (intrinsic) fracture toughness of the material. Substituting for quantities $p_{\mathrm{M}}$ and $\varepsilon_{\mathrm{L}}$ from equations (2.2) and (2.3), respectively, into equation (2.1) yields:

$$
\Delta K_{\mathrm{SS}}=\left(\frac{\psi^{2} \alpha_{\lambda} \sigma_{\mathrm{R}}}{E^{\prime} l}\left(1-\frac{1}{2 \alpha_{\mathrm{d}}^{2}}\right)\right)\left(K_{0} \mu a^{*}\right)
$$

or

$$
\Delta K_{\mathrm{SS}}=C\left(K_{0} \mu a^{*}\right)
$$

where $C$ encompasses all of the intrinsic material parameters. The set of terms, $K_{0} \mu a^{*}$, conceivably depends on the loading rate. Firstly, the initial fracture toughness, $K_{0}$, may be loading rate dependent, based upon its susceptibility to stress corrosion cracking documented in stress intensity-crack velocity experiments [18]. Secondly, the rate dependence of $\mu$ is well established [19]. Finally, returning to Fig. 2, toughening contributions from debonding and pullout to establish $a^{*}$ could depend upon loading rate in the following manner. Consider the alternative cases of incomplete debonding and/or partial pullout prior to fracture. If the bridging grain debonds fully but is fractured in a transgranular fashion prior to complete pullout, the pullout curve will be cut off at a smaller crack opening corresponding to EG in Fig. 2. In such a situation, the net toughening will be the total area bounded by the curve $\mathrm{CP}$ and the straight lines PE and EG, and $a^{*}$ would be consequently reduced. On the other hand, if even before the bridging grain can fully debond, it is fractured at a crack opening of $2 u_{\mathrm{Q}}$ (corresponding to point $\mathrm{Q}$ on the debonding curve), and the fractured grain is pulled out according to pullout curve $\mathrm{QH}$. In this case, the net toughening contribution will be the total area bounded by two curves; $\mathrm{CQ}$ and $\mathrm{QH}$, as shown in Fig. 2. Likewise, $a^{*}$ is reduced. Restated, if toughening contributions from the intrinsic toughness, debonding, or frictional pullout are dependent on loading rates, the net toughening, $\Delta K_{\mathrm{SS}}$, will be dependent on loading rate, $v$, as well. Equation (2.5) can be rewritten as:

$$
\Delta K_{\mathrm{SS}}(v)=C\left(K_{0} \mu a^{*}\right)_{v}
$$

The right hand side of the equation is a product of a rate-independent term $(C)$ and a rate-dependent term $\left(K_{0} \mu a^{*}\right)$. If we compare the net toughening contribution of two specimens of the same material tested at two different loading rates, from equation (2.6):

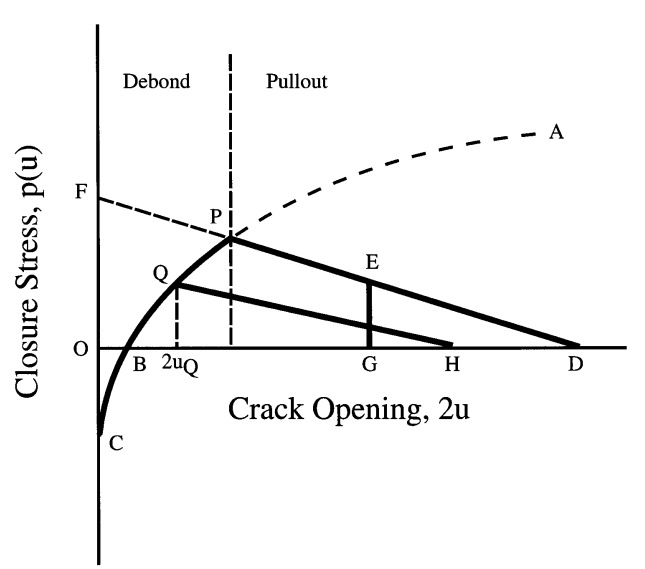

Fig. 2. Schematic of closure stress vs crack opening for a crack bridging material. After Bennison and Lawn [14]. 

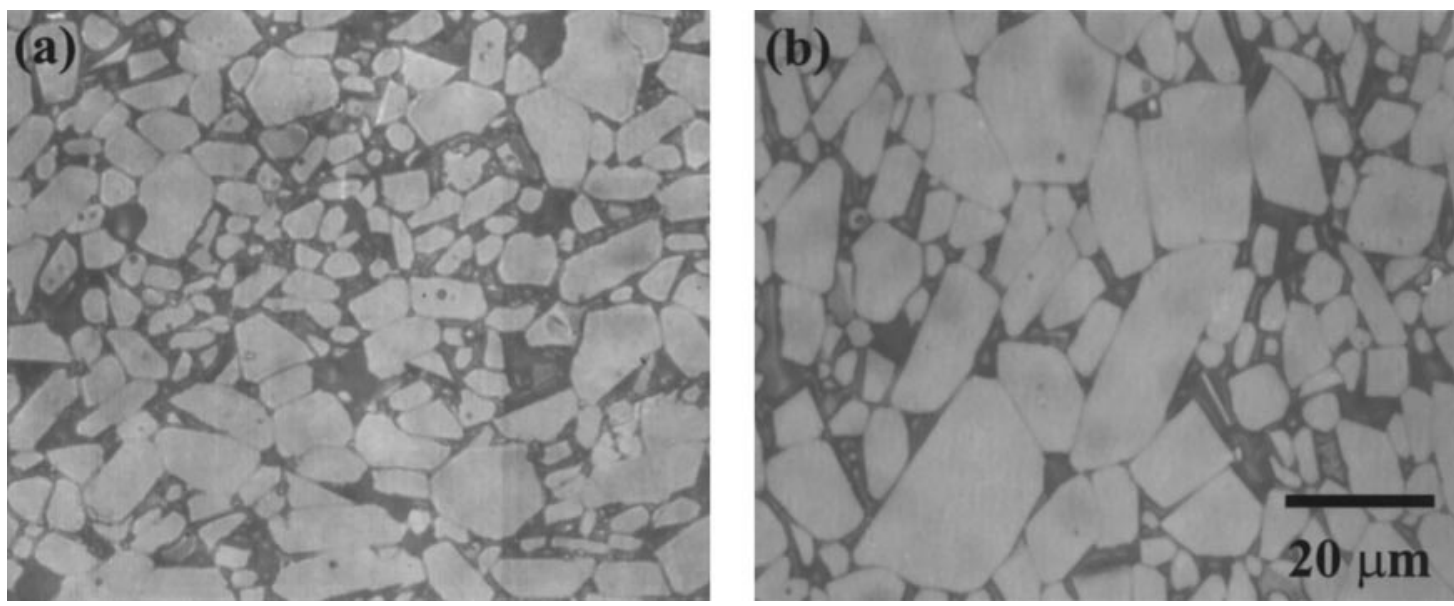

Fig. 3. Microstructures of (a) fine-grained and (b) coarse-grained alumina thermally etched at $1300^{\circ} \mathrm{C}$ in air.

$$
\frac{\Delta K_{\mathrm{SS}}\left(v_{1}\right)}{\Delta K_{\mathrm{SS}}\left(v_{2}\right)}=\frac{\left.K_{0} \mu a^{*}\right|_{\nu_{1}}}{\left.K_{0} \mu a^{*}\right|_{v_{2}}}
$$

ln this study, we experimentally measure the net toughening contribution, $\Delta K_{\mathrm{SS}}$, as a function of loading rate, $v$. Both $K_{0}$ and $a^{*}$ are established from conventional fracture mechanics experiments. Independent measures of the coefficient of friction as a function of sliding speed via tribological testing are performed. Agreement between the two ratios of equation (2.7) will verify the loading rate effects on the net toughening, $\Delta K_{\mathrm{SS}}$.

\section{EXPERIMENTAL DETAILS}

Coors AD 94 alumina (Coors Ceramic Company, Golden, CO) was chosen for these experiments. The as-received (fine-grained) alumina served as a control material. To achieve a coarse-grained microstructure, the fine-grained alumina was heat treated at $1600^{\circ} \mathrm{C}$ for $16 \mathrm{~h}$ in air. Representative microstructures of the fine-grained and coarse-grained materials are shown in Fig. 3. The major impurity shown as the dark grey phase was a silicate glass resulting from the use of sintering aids. The material composition, mean grain size and elastic modulus of both the materials are given in Table 1 . Grain sizes were measured using the line-intercept method [20]. The elastic modulus was measured using a computer-based ultrasonic measurement system (Model 7700, Matek Instruments, Hopkinton, MA).

Table 1. Properties of fine-grained and coarse-grained aluminas

\begin{tabular}{lccc}
\hline AD 94 & Purity (\%wt) & $\begin{array}{c}\text { Mean grain size } \\
(\mu \mathrm{m})\end{array}$ & $E(\mathrm{GPa})$ \\
\hline Fine-grained & 93.3 & 7.0 & 292 \\
Coarse-grained & 93.3 & 18.0 & 309 \\
\hline
\end{tabular}

\subsection{Resistance curve measurements}

Short-double cantilever beam (s-DCB) specimens were employed for resistance curve measurements $[21,22]$. The s-DCB specimens were rectangular plates measuring $31 \times 18 \times 2 \mathrm{~mm}$. To achieve conditions of stable crack growth, the finegrained material was notched using a $250 \mu \mathrm{m}$ thick diamond wheel (Norton Company, Worcester, MA) to a length $a=20 \mathrm{~mm}$; the coarse-grained material to $a=18 \mathrm{~mm}$. Specimens were precracked prior to testing by wedge loading using an alumina wedge. To facilitate crack tip observation during a test all the specimens were polished to a $1 \mu \mathrm{m}$ surface finish ( $1 \mu \mathrm{m}$ Diamond Suspension, Buehler, Lake Bluff, IL).

Precracked s-DCB specimens were tested in displacement control on a servo-electric closed-loop MTS testing machine (Model 808, MTS, Minneapolis, MN). During each test, load, crosshead displacement, crack mouth opening displacement (CMOD) and crack length were measured and recorded with a data acquisition system. The CMOD was measured by a clip gage (Model 632.16 B-20, Minneapolis, MN) mounted on the specimen on either side of the notch in two $500 \mu \mathrm{m}$ deep grooves. A $100 \times$ traveling microscope equipped with a digital micrometer was used to follow the crack tip and measure crack length. Specimens were tested at the constant cross head displacement rates (v) of $0.25,1,4$ and $10 \mu \mathrm{m} / \mathrm{min}$, also referred to here as loading rate. At each loading rate a minimum of three specimens were tested.

The augmented DCB model developed by Kanninen [23] was used to calculate resistance $(R-)$ curves. This model considers a cantilever beam of finite length which is partly free and partly supported by an elastic foundation. For crack propagation under constant displacement conditions the fracture resistance, $K_{\mathrm{R}}$, is given as: 


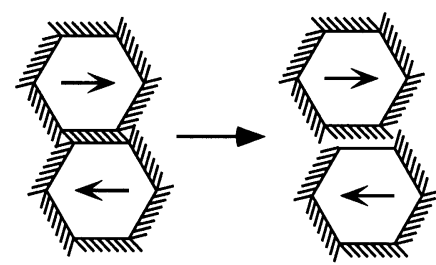

(a) (b)

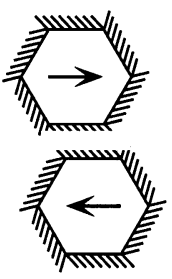

Fig. 4. Schematic of intergranular fracture in alumina. (a) a glass/alumina interface, (b) a glass/glass interface where the hatched area represents the glassy grain boundary phase and the hexagons represent the alumina grains.

$$
K_{\mathrm{R}}=\sqrt{3} E h^{3 / 2} \lambda^{2} \delta \frac{\lambda a \Gamma+\Theta}{2 \lambda^{3} a^{3}+6 \lambda^{2} a^{2} \Lambda+6 \lambda a \Gamma+3 \Theta},
$$

where $a$ is crack length, $h$ is half the beam height ( $=9 \mathrm{~mm}$, in this case), $\lambda$ is a function of the beam height, $\delta$ is the crack opening displacement, $E$ is the elastic modulus of the material and $\Gamma, \Theta$ and $\Lambda$ are trigonometric functions of crack length.

To determine if the formation of crack bridges (as determined by intergranular fracture) is solely a loading rate phenomenon or whether it is affected by the testing environment, specimens of finegrained and coarse-grained materials were tested at two of the four loading rates with a drop of silicone oil (Mcghan Nosil, Carpinteria, CA) at the crack tip. Oil is known to move to the crack tip due to capillary forces and eliminate the environmental effects associated with the presence of moisture in air. For microscopic observations of crack paths of the tested specimens, specimens were unloaded prior to failure. These tested specimens were thermally etched at $1300^{\circ} \mathrm{C}$ for $1 \mathrm{~h}$ to reveal the microstructure.

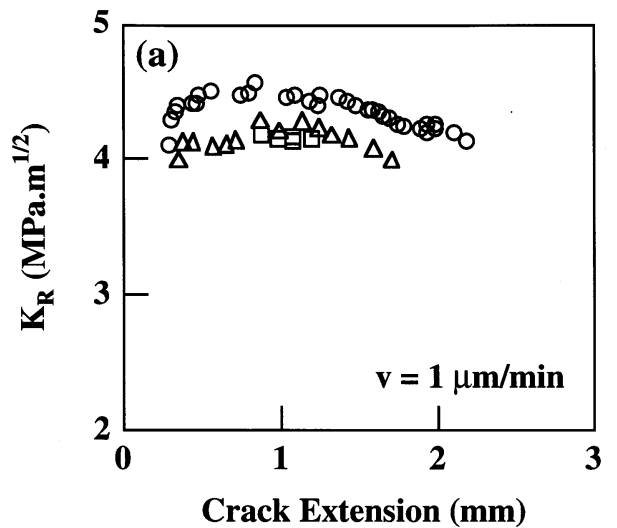

\subsection{Measurements of the coefficient of friction}

Intergranular fracture is a pre-requisite for grain bridging. Intergranular fracture in alumina will take place either along an alumina-glass interface [Fig. 4(a)] or in the glassy intergranular region [Fig. 4(b)]. Hence, frictional sliding along interfaces could transpire along two glass surfaces or along an alumina-glass interface. Both cases are reported in literature [24].

To evaluate rate effects on the sliding of glassalumina and glass-glass interfaces, the coefficient of friction was measured using a ball-on-plate tribotester [25]. In this tribotester, $9.5 \mathrm{~mm}$ spheres of glass or coarse-grained alumina were held fixed, while $24 \times 50 \mathrm{~mm}$ flat glass plates were traversed at controlled speeds. For a known normal force, $N$, produced by the weight of the assembly $(385 \mathrm{~g})$ and an applied weight $(860.1 \mathrm{~g})$, the frictional force, $F$, was measured as a function of sliding speed. The coefficient of friction, $\mu$, is calculated from:

$$
\mu=\frac{F}{N}
$$

For these measurements the glass used (0211, Corning, Corning, NY) was nearly the same composition as that of the glassy phase in alumina. To simulate the surface roughness of the true sliding process, all flat surfaces were abraded with 800 grit $\mathrm{SiC}$ paper. For each measurement a fresh flat surface was used.

\section{RESULTS AND DISCUSSION}

\subsection{Resistance curve results}

Figure 5(a) shows fracture resistance curves for fine-grained alumina tested at the loading rate, $v=1 \mu \mathrm{m} / \mathrm{min}$. Here, the fracture resistance is independent of crack extension; hence, the initial fracture resistance $\left(K_{0}\right)$ is equal to the peak fracture resistance $\left(K_{\max }\right)$. Similar behavior was observed at

Fig. 5. (a) Fracture resistance curves of fine-grained alumina tested at $1 \mu \mathrm{m} / \mathrm{min}$ (three specimens). (b) Peak fracture toughness, $K_{\max }$ vs loading rate for the same material. Solid symbols represent data for the specimens tested in an inert environment. 

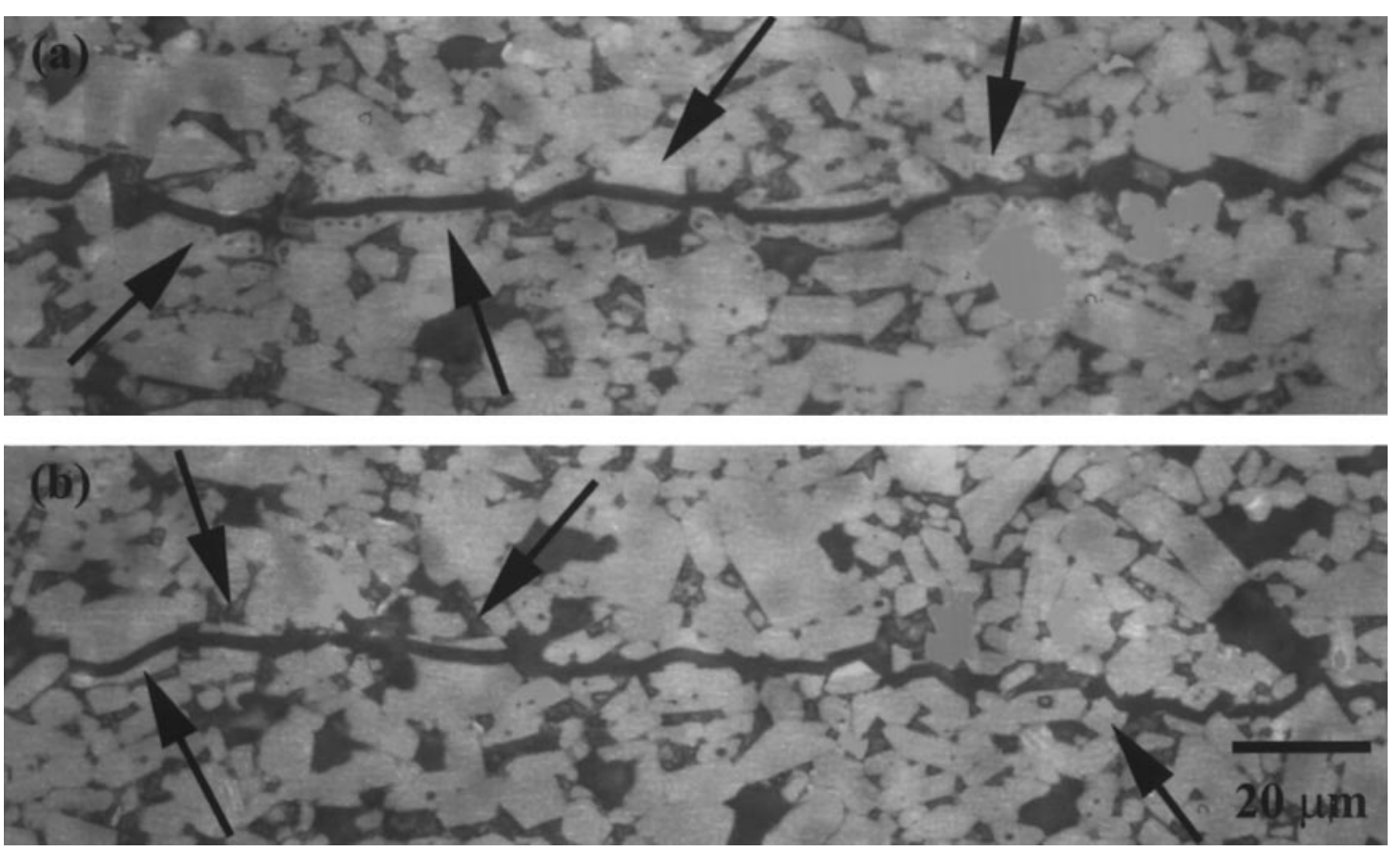

Fig. 6. Crack path micrographs of fine-grained alumina tested at (a) $v=0.25 \mu \mathrm{m} / \mathrm{min}$, (b) $v=4.0 \mu \mathrm{m} /$ min. Arrows in both the micrographs point to sites of transgranular fracture.

0.25 and $4 \mu \mathrm{m} / \mathrm{min}$. At $10 \mu \mathrm{m} / \mathrm{min}$, only two specimens were tested, both of which failed catastrophically. $K_{\mathrm{R}}$ values for these two specimens were calculated from the peak load. $K_{\max }\left(=K_{0}\right)$ is plotted against loading rate in Fig. 5(b) and demonstrates the independence of $K_{\max }$ with loading rate. The average value of $K_{0}$ for the fine-grained material is $4.46 \mathrm{MPa} \mathrm{m}^{1 / 2}$.

Figure 6(a) shows a representative crack path of an fine-grained alumina specimen tested at $0.25 \mu \mathrm{m} / \mathrm{min}$. Arrows point to the sites of transgranular fracture, the predominate fracture mechanism. Similar transgranular fracture is seen for specimens tested at the loading rate of $4 \mu \mathrm{m} / \mathrm{min}$ [Fig. 6(b)]. For transgranular fracture no crack bridging and very little or no toughening enhancement is expected or observed, hence, $R$-curves are flat and $K_{0}=K_{\max }$. These microscopic observations are in agreement with the mechanical properties measurements.

Fracture resistance curves for the coarse-grained material are shown for the four different loading rates in Fig. 7. All the specimens of coarse-grained alumina show rising crack resistance ( $R$-curve) behavior. The initial fracture toughness values, $K_{0}$, were calculated by extrapolating the $K_{\mathrm{R}}$ curves to zero crack extension. These values of $K_{0}$ are plotted against loading rate in Fig. 8(a). Similar to the finegrained material, $K_{0}$ for the coarse-grained material is independent of loading rate and is $4.38 \mathrm{MPa} \cdot \mathrm{m}^{1 / 2}$. The toughening contribution, $\Delta K_{\mathrm{SS}}$ is calculated by subtracting $K_{0}$ from $K_{\max }$ values. $\Delta K_{\mathrm{SS}}$ is plotted against loading rate in Fig. $8(\mathrm{~b})$ and is found to decrease with increasing loading rate.
The crack paths in the coarse-grained specimens show distinct differences compared to the fine-grained specimens. For specimens tested at $0.25 \mu \mathrm{m} / \mathrm{min}$, fracture is mostly intergranular. Cracks run along the grain boundaries, leaving behind intact bridges in the crack wake [Fig. 9(a)]. At the slowest loading rate, full debonding and frictional pullout of the bridging grains and full contributions to toughening occur. For specimens tested at $10 \mu \mathrm{m} / \mathrm{min}$, a mixture of transgranular and intergranular fracture is observed [Fig. 9(b)]. For the coarsegrained material the degree of intergranular fracture decreases with increasing loading rate. The decreasing degree of intergranular fracture implies that the bridging grains fail prior to complete debonding or full frictional sliding. The decrease in intergranular fracture corresponds to fewer bridges in the crack wake and can be correlated to the decrease in the shielding component of the toughness, $\Delta K_{\mathrm{SS}}$.

Results of both the fine-grained and coarsegrained aluminas tested in an inert environment are demonstrated with solid symbols in Fig. 5(b) and Fig. 8, respectively. For both aluminas $K_{0}$ and $K_{\max }$ measured in an inert environment are statistically equivalent to their respective values measured in air. It is clear from these experiments that the observed loading rate effect on toughness is not a reaction rate phenomena.

\subsection{Coefficients of friction}

Figure 10 shows the coefficient of friction as a function of sliding speed measured for glass-alu- 

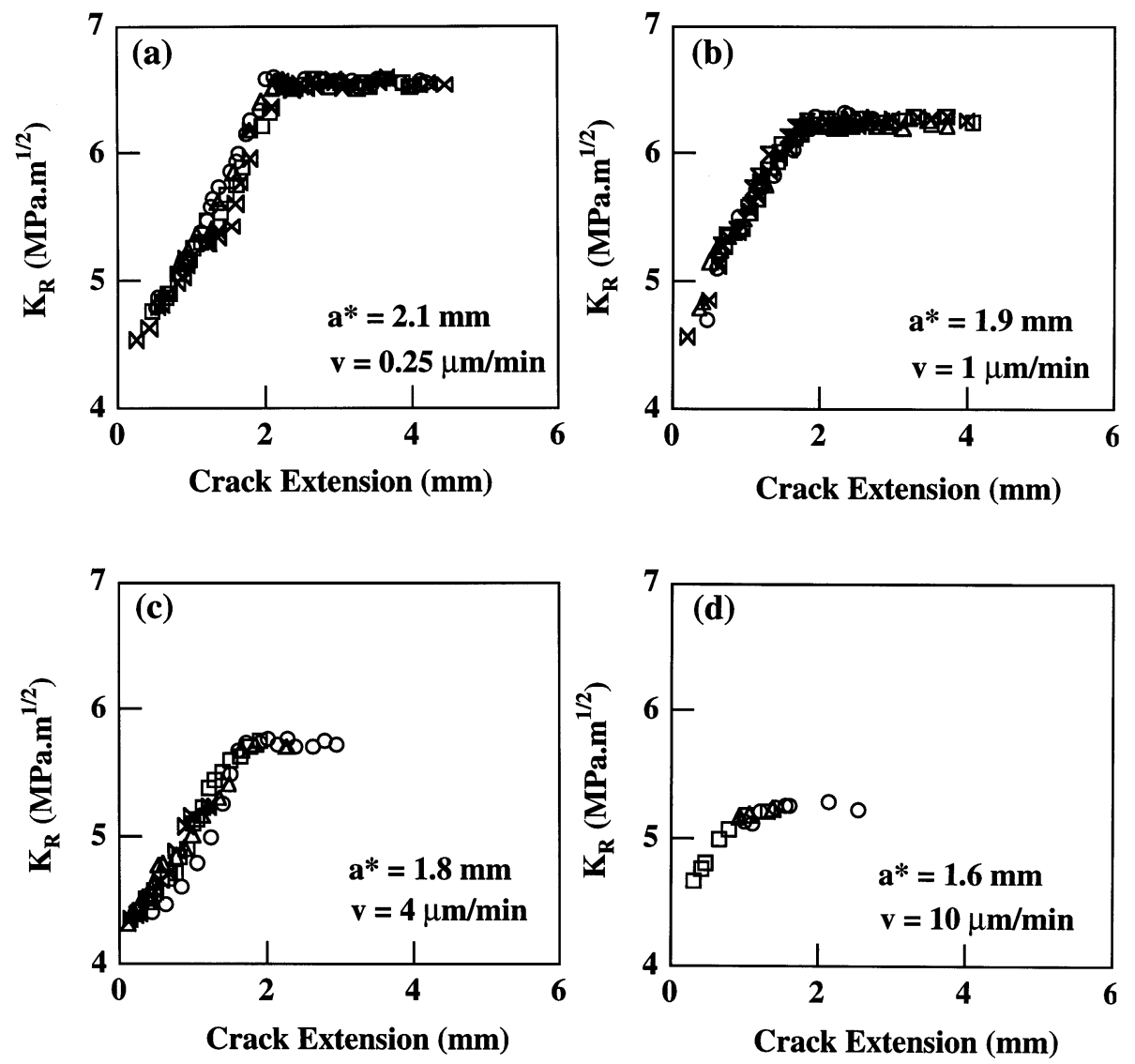

Fig. 7. Fracture resistance curves of the coarse-grained alumina tested at (a) $v=0.25 \mu \mathrm{m} / \mathrm{min}$ (four specimens), (b) $v=1.0 \mu \mathrm{m} / \mathrm{min}$ (five specimens), (c) $v=4.0 \mu \mathrm{m} / \mathrm{min}$ (four specimens), (d) $v=10.0 \mu \mathrm{m} / \mathrm{min}$ (three specimens).

mina and glass-glass surfaces. The coefficient of friction decreases with increasing sliding speed for both material pairs. For each loading rate, $v$, a corresponding steady state crack growth rate $\dot{a}$, was calculated from crack length vs time data acquired in toughness experiments. For example, a loading rate, $v$, of $0.25 \mu \mathrm{m} / \mathrm{min}$ resulted in a steady state crack growth rate, $\dot{a}$, of $0.16 \mathrm{~mm} / \mathrm{min}$ as shown in
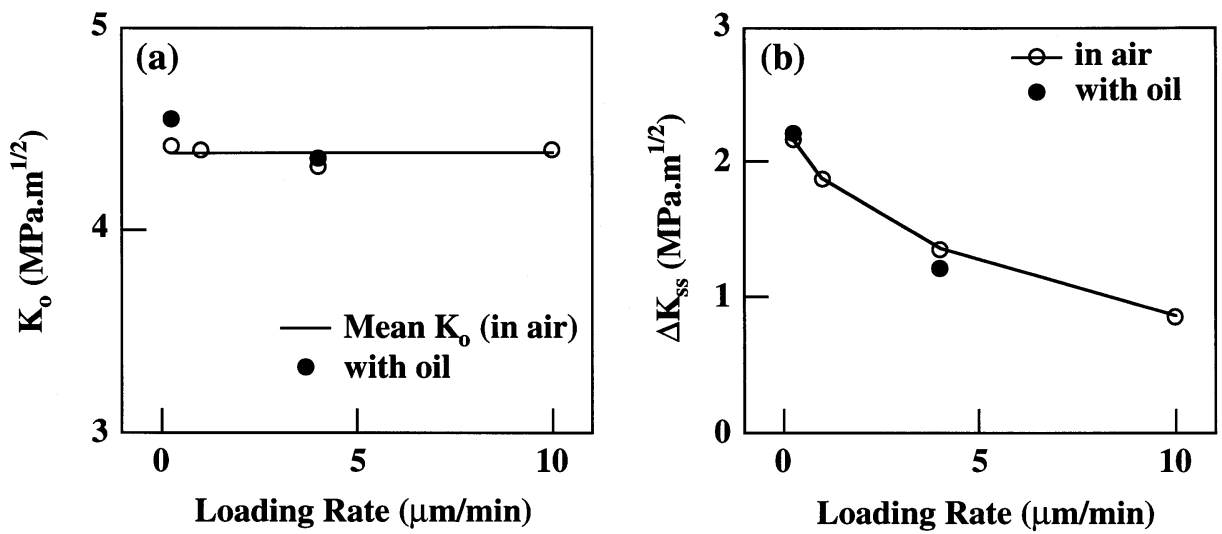

Fig. 8. (a) Initial fracture toughness, $K_{0}$, as a function of loading rate, (b) toughening contribution, $\Delta K_{\mathrm{SS}}$ vs loading rate for coarse-grained alumina. Solid symbols represent data for the specimens tested in an inert environment. 

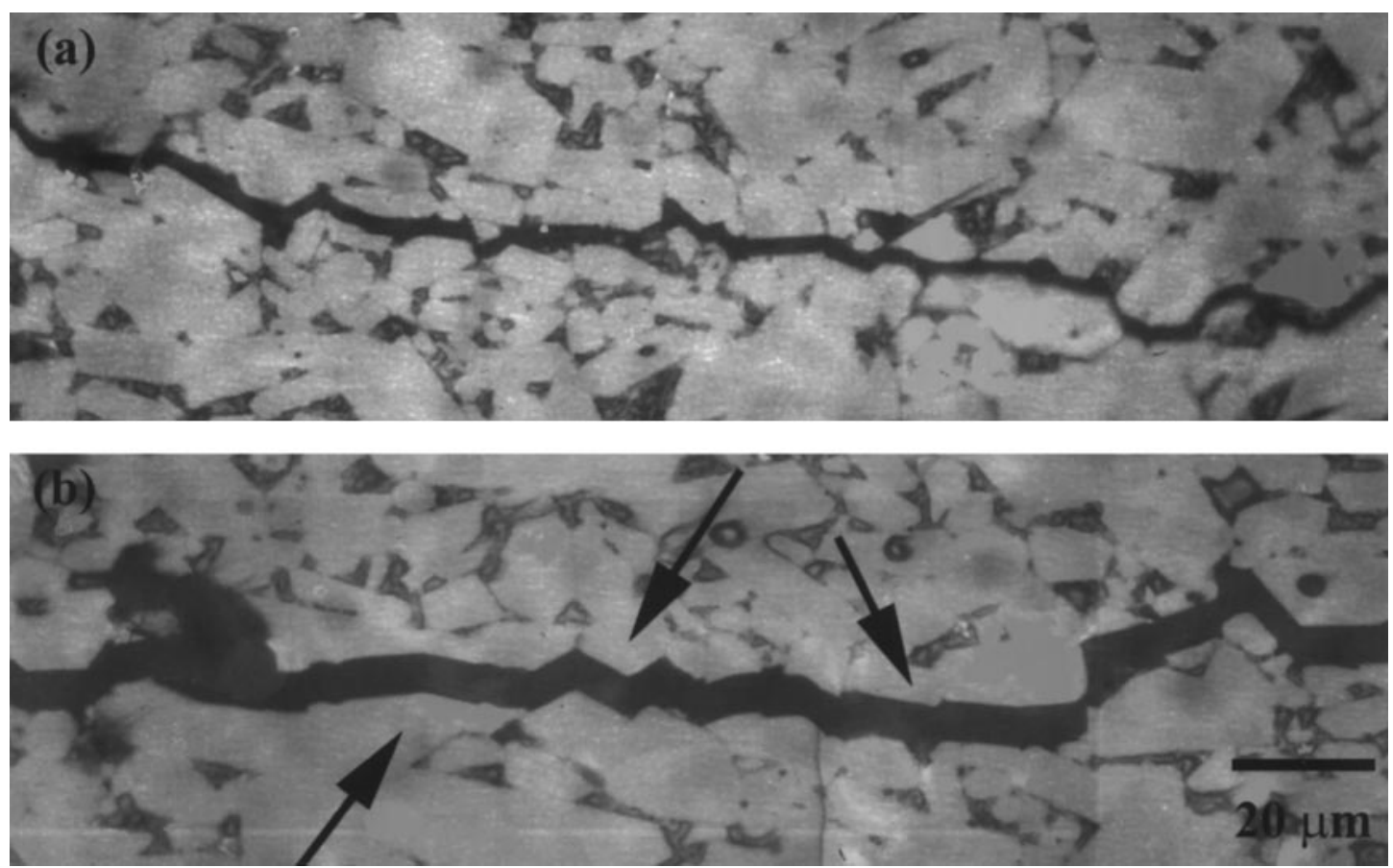

Fig. 9. Crack path micrographs of coarse-grained alumina tested at (a) $v=0.25 \mu \mathrm{m} / \mathrm{min}$, (b) $v=10.0 \mu \mathrm{m} / \mathrm{min}$. Arrows point to the sites of transgranular fracture.

Table 2. By equating $\dot{a}$, to the rate at which the two surfaces are sliding past each other at steady state, the appropriate frictional sliding coefficient, $\mu$, was read from Fig. 10.

\section{THE MODIFIED BRIDGING MODEL}

Measured values of $K_{0}$ and $a^{*}$ from resistance curves of coarse-grained alumina and $\mu$ determined from tribological tests are listed in Table 2. These values permit evaluation of equation (2.7), the crack bridging model modified to include loading

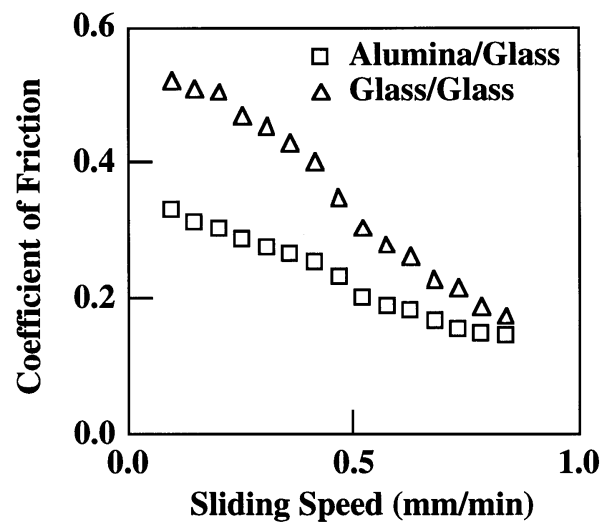

Fig. 10. Coefficient of friction vs sliding speed measured for both alumina-glass and glass-glass systems. rate dependence. Given the invariance of $K_{0}$ with loading rate, equation (2.7) can be simplified further to:

$$
\frac{\Delta K_{\mathrm{SS}}\left(v_{1}\right)}{\Delta K_{\mathrm{SS}}\left(v_{2}\right)}=\frac{\left.\mu a^{*}\right|_{\nu_{1}}}{\left.\mu a^{*}\right|_{\nu_{2}}}
$$

Figure 11 shows the results of the comparison of the $\Delta K_{\mathrm{SS}}\left(v_{1}\right) / \Delta K_{\mathrm{SS}}\left(v_{2}\right)$ with $\left.\mu a^{*}\right|_{\nu_{1}} /\left.\mu a^{*}\right|_{\nu_{2}}$ in equation (5.1) for glass-glass frictional sliding and glass-alumina frictional sliding. Both ratios were normalized with respect to experimental values of specimens tested at the slowest testing speed $(0.25 \mu \mathrm{m} / \mathrm{min})$. Figure 11 clearly shows the contribution to toughening from bridging does depend on loading rate. Our measurements show that the measured toughness ratios are in excellent agreement with theoretical predictions based on Bennison's and Lawn's bridging model modified to include the loading rate influence on $\mu$ and $a^{*}$.

The change in toughness with loading rate derives from both $\mu$ and $a^{*}$, although the larger influence is provided by the change in the coefficient of friction (see Table 2). Returning to the closure stress-crack opening profiles presented in Section 2, we now examine how the bridging closure stress profile is related to measured parameters, $\mu$ and $a^{*}$. With decreasing $\mu$, the debonding curve as well as the frictional pullout curve both shift downward as seen in Fig. 12. The debonding curve scales with $\mu^{1 / 2}$ while the pullout curve scales linearly with $\mu$ [14]. Hence, the toughening contribution by any 
Table 2. $K_{0}, a^{*}$ and $\mu$ for coarse-grained alumina

\begin{tabular}{lccccc}
\hline $\begin{array}{l}\text { Loading rate, } v(\mu \mathrm{m} / \\
\text { min) }\end{array}$ & $\begin{array}{c}\text { Crack growth rate, } \dot{a} \\
(\mathrm{~mm} / \mathrm{min})\end{array}$ & $K_{0}\left(\mathrm{MPa} \cdot \mathrm{m}^{1 / 2}\right)$ & $a^{*}(\mathrm{~mm})$ & $\mu$ (glass-glass) & $\mu$ (glass-alumina) \\
\hline & 0.16 & 4.4 & 2.1 & 0.51 & 0.32 \\
1 & 0.22 & 4.4 & 1.9 & 0.49 & 0.31 \\
4 \\
10 & 0.38 & 4.3 & 1.8 & 0.32 & 0.26 \\
\hline
\end{tabular}

bridging grains is diminished with increasing rate. Recall, however, from microscopic fracture observations that the number of bridging grains also is reduced with increasing rate. This is manifest in a decrease in $a^{*}$, and shifts the critical crack opening, $2 u^{*}$, to smaller values, also shown in Fig. 12. The total toughening is then reduced in two ways, firstly, by a diminution of the effectiveness of the remaining bridges, and secondly, and to lesser extent, by a reduction in the number of bridges. What still remains a puzzle is why more grains fracture in an intergranular fashion at faster rates if the sliding coefficient of friction decreases.

From this study it is demonstrated that measured resistance curve and the corresponding toughening due to bridging are rate dependent. Thus, it is more appropriate to write the basic $R$-curve equation (1.1) as:

$$
K_{\max }(v)=K_{0}+\Delta K_{\mathrm{SS}}(v)
$$

where the net toughness of a bridging ceramic, $K_{\max }$ is a rate-dependent quantity comprised of two factors: one rate-independent term, the intrinsic toughness of the material, $K_{0}$, and a second rate dependent term, the net toughening contribution, $\Delta K_{\mathrm{SS}}$, due to bridging. With increasing loading rate, the peak toughness and the net toughening contribution decrease approaching the flat resistance curve seen for the fine-grained counterpart.

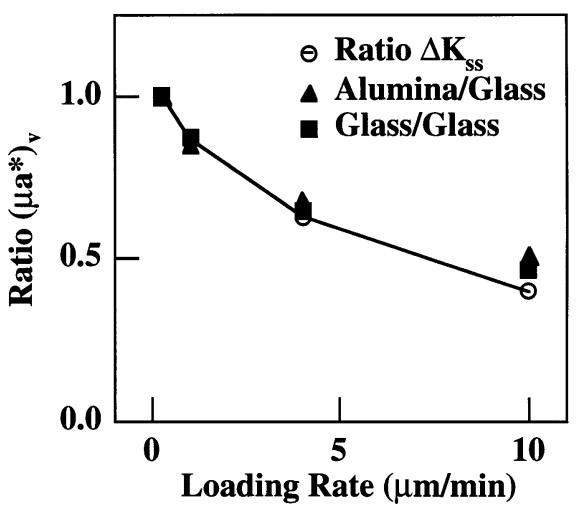

Fig. 11. Comparison of $\Delta \mathrm{K}_{\mathrm{SS}}\left(v_{1}\right) / \Delta \mathrm{K}_{\mathrm{SS}}\left(v_{2}\right)$ and $\left.\mu a^{*}\right|_{\nu_{1}} /\left.\mu a^{*} n\right|_{\nu_{2}}$ plotted against loading rate.

\section{SUMMARY AND IMPLICATIONS}

Experiments are performed to characterize the effect of loading rate on toughening due to crack bridging in alumina. In fine-grained and coarsegrained aluminas, the initial fracture toughness, $K_{0}$, is independent of loading rate. In the case of coarse-grained alumina, the toughening contribution from crack bridging grains, $\Delta K_{\mathrm{SS}}$, decreases with increasing loading rate. The fine-grained material shows primarily transgranular fracture for all loading rates in this study while coarse-grained alumina specimens show highly intergranular fracture for slow loading rates and an increasing degree of transgranular fracture with increasing loading rate. Experiments performed in an inert environment demonstrate that the change from intergranular to transgranular fracture is solely a loading rate phenomenon and is independent of environment. The observed rate dependence is explained on a theoretical basis from Bennison's and Lawn's bridging model modified to account for the dependence of the frictional sliding coefficient, $\mu$, and crack length $a^{*}$, on velocity.

The dependence of shielding on loading rate reported here may pose new design challenges for quasi-brittle materials. Although laboratory testing at rates where shielding contributions can be easily discerned and studied is meritorious, it may not offer accurate toughness values for life prediction. The present observations suggest that steady-state

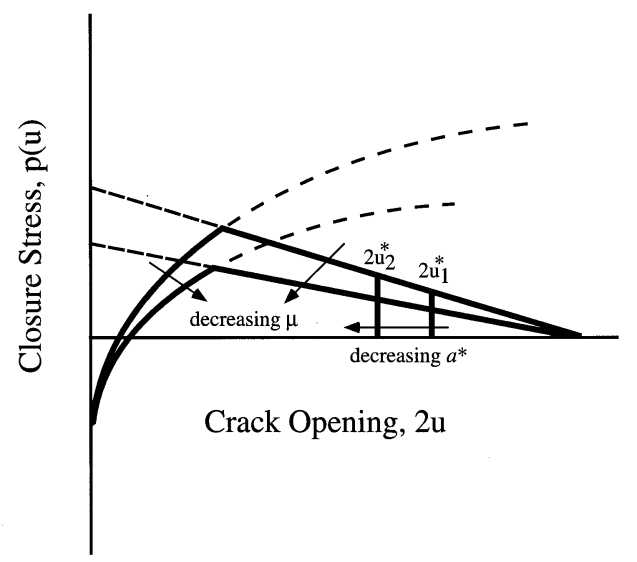

Fig. 12. Schematic of closure stress vs crack opening for a crack bridging material as influenced by coefficient of friction, $\mu$, and, $a^{*}$, the critical crack length at which the $R$ curve reaches steady state. 
toughness values measured at laboratory testing rates may significantly overestimate the in-service toughness.

Acknowledgement-This work was supported by the National Science Foundation Center for Advanced Cement Based Materials at Northwestern University.

\section{REFERENCES}

1. Swanson, P. L., Fairbanks, C. J., Lawn, B. R., Mai, Y. W. and Hockey, B. J., J. Am. Ceram. Soc., 1987, 70, 279 .

2. Becher, P. F., J. Am. Ceram. Soc., 1991, 74, 255.

3. Evans, A. G. and Marshall, D. B., Acta metall. mater., 1989, 37, 2567.

4. Newkirk, M. S., Urquhart, A. W. and Zwicker, H. R., J. Mater. Res., 1986, 1, 81

5. Lawn, B. R., J. Am. Ceram. Soc., 1983, 66, 83.

6. Okada, A., Hiroski, N. and Yoshimura, M., J. Am. Ceram. Soc., 1990, 73, 2095.

7. Padture, N. P., J. Am. Ceram. Soc., 1994, 77, 519.

8. Chantikul, P., Bennison, S. J. and Lawn, B. R., J. Am. Ceram. Soc., 1993, 76, 2419.

9. Grimes, R. E., Kelkar, G. P., Guazzone, L. and White, K. W., J. Am. Ceram. Soc., 1990, 73, 1399.

10. Steinbrech, R. W. and Schmenkel, O., J. Am. Ceram. Soc., 1988, 71, C271.
11. Steinbrech, R. W., Reichl, A. and Schaarwachter, W., J. Am. Ceram. Soc., 1990, 73, 2009.

12. Steinbrech, R. W., Dickerson, R. M. and Kleist, G., in: Toughening Mechanisms in Quasi-Brittle Materials, ed. S. P. Shah, 1991

13. Mai, Y. W. and Lawn, B. R., J. Am. Ceram. Soc., 1987, 70, 289.

14. Bennison, S. J. and Lawn, B. R., Acta metall. mater., 1989, 37, 2659.

15. Darroudi, T. and Landy, R. A., Am. Ceram. Soc. Bull., 1987, 66, 1139.

16. Knickerbocker, S. H., Zangvil, A. and Brown, S. D., J. Am. Ceram. Soc., 1984, 67, 365.

17. Sorensen, B. F. and Holmes, J. W., J. Am. Ceram. Soc., 1996, 79, 313.

18. Michalske, T. A. and Bunker, B. C., J. Am. Ceram. Soc., 1986, 69, 721.

19. Moore, D. F., Principles and Applications of Tribology, 1975.

20. Russ, J. C., Practical Stereology, 1986.

21. Reichl, A. and Steinbrech, R. W., J. Am. Ceram. Soc., 1988, 71, C299.

22. Readey, M. J., Heuer, A. H. and Steinbrech, R. W., Mater. Res. Soc. Symp. Proc., 1987, 78, 107.

23. Kanninen, M. F., Int. J. Fract., 1973, 9, 83.

24. Zagrebelny, A. V. and Carter, C. B., 99th Ann. Meet. Am. Ceram. Soc. SXVI-035-97, Cincinnati, OH, 1997.

25. Gohar, R., Experimental Methods in Tribology, London, 1968, p. 43. 